\title{
BMJ Open How a deliberative approach includes women in the decisions of screening mammography: a citizens' jury feasibility study in Andalusia, Spain
}

\author{
José M Baena-Cañada, ${ }^{1}$ Violeta Luque-Ribelles, ${ }^{2}$ Alicia Quílez-Cutillas, ${ }^{3}$ \\ Petra Rosado-Varela, ${ }^{4}$ Encarnación Benítez-Rodríguez, ${ }^{5}$ \\ Soledad Márquez-Calderón, ${ }^{6}$ Juan Manuel Rivera-Bautista ${ }^{7}$
}

To cite: Baena-Cañada JM, Luque-Ribelles V, QuílezCutillas A, et al. How a deliberative approach includes women in the decisions of screening mammography: a citizens' jury feasibility study in Andalusia, Spain. BMJ Open 2018;8:e019852. doi:10.1136/ bmjopen-2017-019852

- Prepublication history and additional material for this paper are available online. To view these files, please visit the journal online (http://dx.doi. org/10.1136/bmjopen-2017019852).

Received 29 September 2017 Revised 5 March 2018 Accepted 10 April 2018

Check for updates

For numbered affiliations see end of article.

Correspondence to Dr José M Baena-Cañada; jmbaenacanada@gmail.com

\section{ABSTRACT}

Objectives To verify whether a citizens' jury study is feasible to the Andalusian population and to know if women, when better informed, are able to answer the research question of whether the Andalusian Public Health System must continue offering screening mammography to women aged $50-69$. The reasons for the pertinent decision and recommendations to the political authorities will be stated.

Design Qualitative research study with the methodology of citizens' jury.

Setting Breast cancer screening programme in Andalusia (Spain).

Participants Thirteen women aged 50-69 with secondary school or higher education accepted to participate as a jury. Two epidemiologists were the expert witnesses. The main researcher was the neutral moderator.

Interventions Jury met on Monday, 15 February 2016. The moderator indicated to the jury that it had to assess the screening programme's key benefits and main harm. On Tuesday, 16 February, the expert witnesses positioned for and against the programme. On Thursday, 18 February, the jury deliberated, reached final conclusions, submitted its vote and stated its recommendations to politicians. The deliberation session was transcribed and analysed with the support of ATLAS.ti.5.2 software.

Primary and secondary outcome measures Feasibility in the Andalusian population, women's vote and opinion, reasons for votes and recommendations to political authorities.

Results Eleven participants voted yes and two voted no. There are three reasons to vote 'yes': health, the test nature, and individual freedom. Some women invoke the lack of efficacy and the cost to justify their negative vote, at least in universal terms. On completion, they made suggestions to be submitted to the pertinent authorities for the improvement of information, psychology services and research.

Conclusions The deliberative strategy is feasible and causes a favourable positioning regarding screening mammography, although information changes the opinion of some women, who desire informed decision making and to keep or increase medicalisation in their lives.
Strengths and limitations of this study

- Consolidated criteria for reporting qualitative studies were followed, and the most important elements of the citizens' jury have been addressed.

- The deliberative process was planned, with a description of the selection and roles of the research team and experts, and a description of the recruitment strategy and the characteristics and instructions for the jury.

- The technical and procedural information is available and clearly documented.

- The study was designed as a research project, and since there was no representation of participating women on the research team, their opinion and possible critical perspective with respect to the study's design and performance have not been considered.

- The information submitted arises from a sole process of deliberative democracy, which is why it will be necessary to apply, as programmed, other methodological strategies allowing for the gathering of more information to fulfil the categories and be certain that the collected information covers every possibility.

\section{INTRODUCTION}

There is increasing evidence indicating that screening mammography may constitute a low-value service where benefits do not exceed harm and cost. ${ }^{1}$ Some women will benefit, while others would be harmed. ${ }^{2}$ However, public perception is not realistic. ${ }^{3}$ For instance, women in Spain accept the invitation to participate in screening mammography and receive little information ${ }^{4}$ and, in general, tend to overestimate the benefits ${ }^{5}$ and are not involved in the physical or psychological impact caused by overdiagnosis and false positives. ${ }^{6} 7$ Any help in decision making related to screening mammography potentially could lead to an informed decision, ${ }^{8-10}$ but it is not yet clear how to apply such information in an optimal 
fashion. ${ }^{9}$ In this context, there are still arguments in favour of screening mammography ${ }^{11}$ and it has not been removed in western countries, except for Switzerland. ${ }^{12}$ Spain has a National Health System, but every region is autonomous regarding decisions on screening mammography programme coverage. In Andalusia, a population-based screening programme invites women every 2 years, through a letter. In 2013, a report ${ }^{13}$ was prepared and served to fix the age between 50 and 69 , ceasing to invite women aged 45-49 in districts where they were invited before.

Citizens' juries gather a group of citizens, randomly chosen, to discuss a particular topic. They are exposed to information and opinions on such topics for several days, in which information and opinions are derived from witnesses selected because of their expertise or because they represent their interests. Along with a moderator qualified to guarantee a fair process, jury members have the opportunity to question the witnesses and, after a deliberation process, they reach a decision and make recommendations to the pertinent authorities. The latter are compelled to provide an answer, either by acting pursuant to the citizens' report or by explaining why they do not agree. ${ }^{14}$ The implementation of citizens' juries has been proposed as a tool to provoke the population's position on public health issues involving scientific controversy, as well as for political decision-making purposes. ${ }^{1516}$ Democratic deliberation is useful for participation in health affairs where it is difficult to obtain an individual and informed consent, where consent represents the community. ${ }^{17}$

We have designed, carried out and analysed a citizens' jury-type deliberative democracy study to verify whether it is feasible in the Andalusian population. We have established the following as secondary objectives: to know if women, when better informed via the information provided during the citizen jury process, are able to answer the research question of whether the Andalusian Public Health System (SSPA) must continue offering screening mammography to women aged 50-69, to know the reasons for the pertinent decision and recommendations to the political authorities.

\section{METHODS}

Research protocol (see online supplementary file 1) was approved and all participants gave written informed consent. Their names as referred to in the quotations are fictitious to guarantee confidentiality.

Primary and secondary outcome measures were feasibility in the Andalusian population (if performance and execution of the study were carried out without any problem as planned, if the study was accepted by women and if its objectives were reached), women's votes and opinions, the reasons for such votes and recommendations to the political authorities.

\section{Jury selection}

A sample of 70 women aged 50-69, with secondary school or higher education, and without any relationship established between them or with the researchers prior to study commencement, was selected from the list of invitations of the breast cancer screening programme. Telephone contact started 3 months before the process. They were excluded if, after three attempts on different days, it was not possible to contact them. In the first contact, information on features and purposes was provided and, if they accepted, they were contacted a month before and a week before for confirmation. The purpose was to recruit at least 12 women.

\section{Expert witness selection}

Two expert epidemiologists (female) defended the positions for and against screening mammography. The one positioned in favour works at the Provincial Cancer Registry of Cadiz (EBR) and was selected because she has been a member of the research team for many years. The one against (SMC) was selected due to her expertise in the development of the Andalusian screening mammography programme and because of her critical position toward it. The main researcher (male) in this study was the neutral moderator (JMBC).

\section{Documentation preparation}

Informed consents and an information gathering sheet with respect to the participants' features were prepared. The research team and the expert witnesses prepared four documents to be delivered to the jury (see online supplementary file 1). (1) General information document and a presentation for the jury members regarding the screening mammography. (2) Document with arguments for and against mammographies, containing the experts' presentations. For its preparation, the report published by the General Secretariat of Public Health, Social Inclusion and Life Quality was employed as a guide. $^{13}$ (3) An information document regarding the Andalusian early detection of breast cancer programme available at http://www.juntadeandalucia.es/servicioandaluzdesalud/principal/documentosacc.asp? pagina $=\mathrm{gr}$ _sabermas_cancermama. (4) Presentation with recommendations for deliberation.

\section{Process}

The jury members met three afternoons for 4 hours at a hotel in the city. On the first day, introductions were performed, the study's features and purposes were explained, doubts were resolved, informed consents were signed and sociodemographic information questionnaires were fulfilled. They were provided with a dossier containing the described information. The moderator indicated to the jury that it had to assess the key benefits of the screening programme (breast cancer mortality reduction), the main harm (overdiagnosis, overtreatment and false positives), and other benefits and harms. To that effect, a presentation was made to understand the arguments for and against that would be presented the next day. The opportunity to resolve doubts was granted. 
On the second day, the experts made their presentations using a PowerPoint presentation (see online supplementary file 3) for and against the programme, and the jury asked questions. The moderator led the debate and discussion.

On the last day, the jury discussed the presentations and programme without the presence of the experts or moderator and reached a conclusion. They issued their vote and wrote suggestions to political decision makers.

During the 3 days, an observer expert in qualitative research (VLR) took notes on the sessions without participating actively. The entire process was supervised by an expert in Bioethics (JMRB). All the sessions were audio and visual recorded. A gift valued at 20 Euros was given to each participant.

\section{Information analysis}

On transcription of the deliberation session by independent parties (see acknowledgements), the session was analysed with the support of ATLAS.ti.5.2 software. A systematic reading of the information was performed, the categories derived from the deliberation were identified and, in this paper, only the analysis of the category 'opinion on whether the SSPA must continue offering mammographies to women aged 50-69' is presented. The deliberation session was deconstructed, assigning and reducing the information in this category. The information later was reconstructed and summarised to conclude with its interpretation. A theoretical approach based on health psychology from a feminist approach ${ }^{18}$ was established.

A researchers/analyst's triangulation was performed to reduce the distortion of the information interpretation and to increase the validity of results. To that effect, a person not related to the team, an expert in qualitative information analysis and health social psychology was incorporated. Such individual was provided with a detailed report on the results and, by means of a Likert-type scale from 1 to 5 , had to assess the relevance of categories, subcategories and identified features, their definitions and the examples provided. This person also scored the information interpretations. Among their suggestions, we found the following: to gather and remove some categories, to deepen the definition of others and to provide more examples in some categories and subcategories for being insufficiently based on the information. Their recommendations were followed.

\section{Patient and public involvement}

The study was designed as a research project, and since there was no representation of participating women on the research team, their opinion and possible critical perspective with respect to the study's design and performance have not been considered.

A process of verification by informants (member checking) was carried out. The participants were given an abbreviated report on the results where they had to score, in a Likert-type scale from 1 to 5 , the adjustment

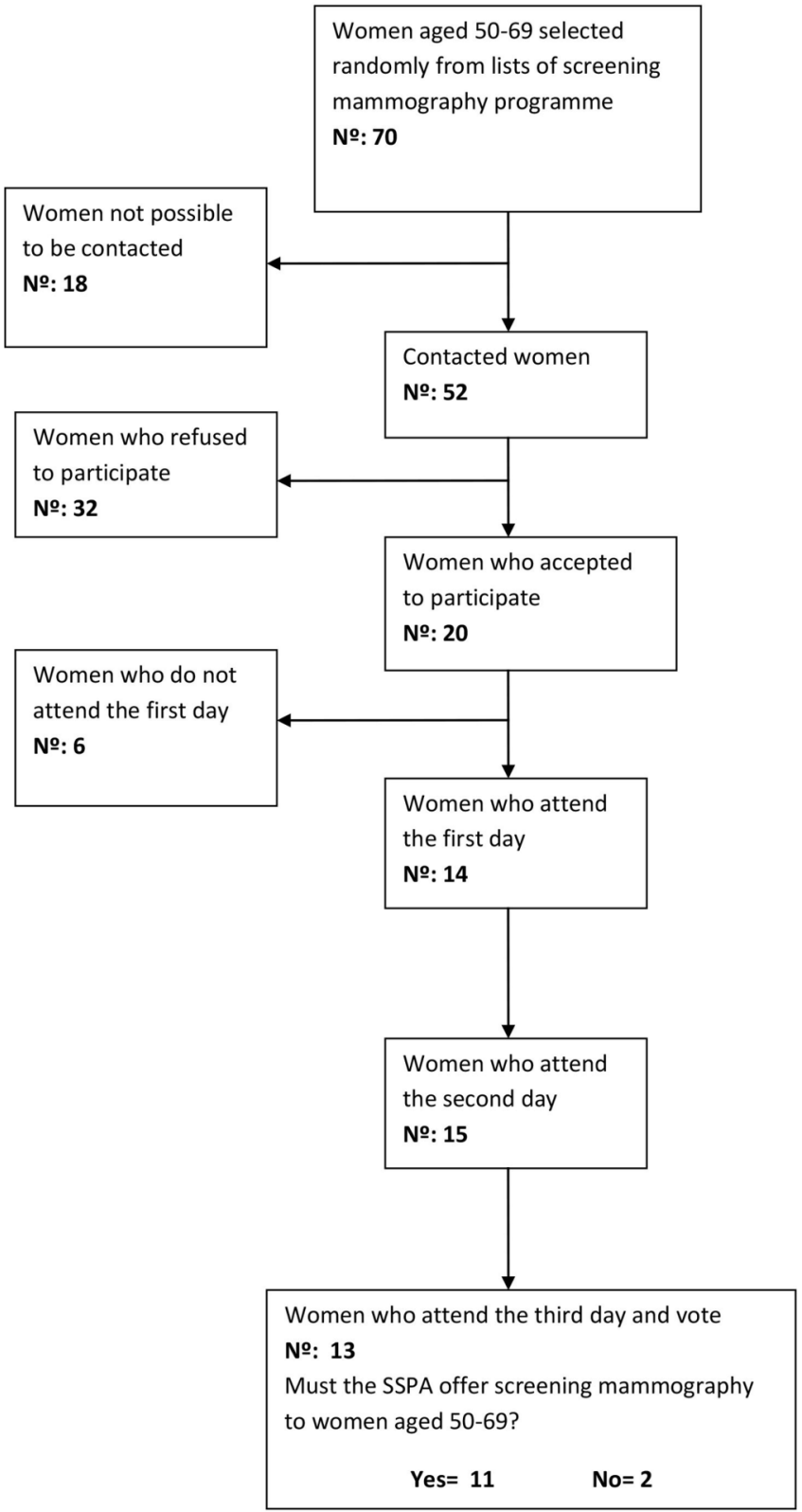

Figure 1 Flowchart of jury recruitment. SSPA, Andalusian Public Health System.

and sufficiency of the definition of categories and subcategories and the relevance of quotations by means of which categories were justified and illustrated. Six scores were obtained that, in general, agreed with the interpretation of the information and participants stated they recognised their voices in the report.

\section{RESULTS}

Figure 1 shows a flowchart of jury recruitment and table 1 shows its main features. Attendance was consistent since 13 women attended 3 days. None of the 13 women who deliberated and voted missed any information provided on the first and second days. Eleven of them voted 'yes' and two voted 'no' to the question of whether the SSPA must offer mammographies to women aged 50-69. 
Table 1 Jury members' features

\begin{tabular}{lc}
\hline Age (median and category) & $\mathbf{5 5}$ (51-65) \\
\hline Level of education & \\
\hline Secondary & 5 \\
University & 8 \\
\hline Working status & \\
$\quad$ Active & 8 \\
\hline Unemployed & 3 \\
\hline Pensioner & 2 \\
\hline Marital status & \\
\hline Married & 10 \\
\hline Separated & 2 \\
\hline Widow & 1 \\
\hline Do you have a mammography performed regularly? \\
\hline Yes & 12 \\
\hline No & 1 \\
\hline You have a mammography performed with & \\
\hline Public screening programme & 11 \\
\hline Private healthcare & 1 \\
\hline Both & 1 \\
\hline Previous mammography rounds & 1 \\
\hline 1 & 0 \\
\hline 2 & 2 \\
\hline 3 & 1 \\
\hline 4 & 6 \\
\hline 5 & \\
\hline$>5$ & \\
\hline
\end{tabular}

Family history of breast cancer

$\begin{array}{ll}\text { Yes } & 4 \\ \text { No } & 9\end{array}$

Previous favourable opinion on screening mammography

$\begin{array}{lr}\text { Yes } & 13 \\ \text { No } & 0\end{array}$

The reasons why participants think mammographies must continue being offered form three groups: health, test nature and individual freedom (table 2). Different opinions are observed regarding coverage among those who believe they must continue being offered; some women deem the universal nature necessary while others believe that mammographies should be offered on demand. There are participants who mention lack of efficacy and high cost to justify why they must not continue being offered. Tables 3 and 4 present some women's indicative quotations.

\section{Health as a reason to continue offering screening} mammography

Mortality reduction arises as a reason for which some participants believe it must continue being offered
Table 2 Categories on whether the Andalusian Public Health System must continue offering screening mammography

\begin{tabular}{|c|c|c|c|}
\hline Category & Subcategory & Features & Indicators \\
\hline \multirow[t]{11}{*}{ Yes } & \multirow[t]{9}{*}{ Reason } & \multirow[t]{3}{*}{ Health } & Mortality reduction \\
\hline & & & $\begin{array}{l}\text { Prevents 'greater } \\
\text { harm' }\end{array}$ \\
\hline & & & $\begin{array}{l}\text { Few negative } \\
\text { consequences }\end{array}$ \\
\hline & & \multirow{4}{*}{$\begin{array}{l}\text { Nature of the } \\
\text { test }\end{array}$} & Diagnostic test \\
\hline & & & $\begin{array}{l}\text { Absence of } \\
\text { alternatives }\end{array}$ \\
\hline & & & High efficacy \\
\hline & & & Public good \\
\hline & & \multirow{2}{*}{$\begin{array}{l}\text { Individual } \\
\text { freedom }\end{array}$} & Women's freedom \\
\hline & & & $\begin{array}{l}\text { Capacity and right } \\
\text { to make decisions }\end{array}$ \\
\hline & \multirow{2}{*}{$\begin{array}{l}\text { Type of } \\
\text { offering }\end{array}$} & \multirow{2}{*}{\multicolumn{2}{|c|}{$\begin{array}{l}\text { On demand } \\
\text { Universal }\end{array}$}} \\
\hline & & & \\
\hline No & Reason & \multicolumn{2}{|l|}{$\begin{array}{l}\text { Lack of } \\
\text { efficacy } \\
\text { High cost. }\end{array}$} \\
\hline
\end{tabular}

between 50 and 69 years old. During deliberation, there were different opinions on whether mortality reduction is significant. Rosario mentions that the reduction degree is not an aspect to be considered and that any reduction is acceptable in regard to human lives (table 3). Participants refer to mammography's diagnostic nature when they indicate that mammography may prevent greater harm (note Rosa's words in table 3). They think participation in screening facilitates an early diagnosis and improves treatment possibility (see María's quotation in table 3), prevents any harm derived from the advanced cancer stage and helps extend a decent life. Furthermore, reference is made to the negative consequences; some participants believe they are few and minimise them, such as radiation. They consider that some of the negative consequences are also present in other tests and this justifies the continuance of mammography (table 3 ).

\section{The nature of the screening test as a reason to continue offering mammographies}

Some participants believe screening mammography is a diagnostic test. They see it as the only efficient test to detect breast cancer, which they invoke as a reason to support it. Consequently, they think every kind of risk, side effect or error possibility is reasonable. Milagros, even when she recognises that overdiagnosis may be a risk, appreciates that it seldom occurs. That is how she justifies that it must continue being offered (table 3). Moreover, there is the idea that screening is a preventive test, as another argument in favour of the offering thereof. However, it is based on the wrong idea that screening mammography 
Table 3 Indicative quotations: reasons to continue and to not continue offering screening mammographies

\begin{tabular}{|c|c|}
\hline Jury member & Indicative quotation \\
\hline & Health as a reason to continue offering screening mammography \\
\hline Juana & $\begin{array}{l}\text { I'm in favour of its continuance, because as from the moment it reduces mortality, I believe it must be } \\
\text { offered. }\end{array}$ \\
\hline Rosario & $\begin{array}{l}\text {...The fact that it reduces mortality, even for two people, is enough to me, because if I'm one of those } \\
\text { people, I will tell you whether it is worth it or not. }\end{array}$ \\
\hline \multirow[t]{2}{*}{ Milagros } & $\begin{array}{l}\text {...it's OK because negative things are very few ....Because, the negative, what is it? The radiation? Well, } \\
\text { we already know it's a normal X-ray... }\end{array}$ \\
\hline & The nature of the screening test as a reason to continue offering screening mammography \\
\hline Juana & $\begin{array}{l}\text {...Mammography itself, in my opinion, is really good because it detects any possible problem, so you } \\
\text { say 'it may find out a problem'. }\end{array}$ \\
\hline \multirow[t]{2}{*}{ Milagros } & $\begin{array}{l}\text { We must take into account that overdiagnosis is one out of seventy-seven, I mean, it's really small, so } \\
\text { death is one out of one thousand but overdiagnosis, which is one of the negative things, is one out of } \\
\text { seventy-seven, it's very small, the fact that one out of seventy-seven is overdiagnosed is really small, I } \\
\text { think it's a lottery. } \\
\text {...I wouldn't remove it, because it's a public good ... in addition, it's up to you, because it's voluntary. }\end{array}$ \\
\hline & Individual freedom as a reason to continue offering screening mammography \\
\hline \multirow[t]{2}{*}{ Carmen } & Yes, yes, I think women are free to make decisions. \\
\hline & Lack of efficacy as a reason not to continue offering screening mammography \\
\hline Juana & $\begin{array}{l}\text { In favour of women being provided with enough information so that they can decide freely, considering } \\
\text { the pros and cons, whether to have it made or not voluntarily. }\end{array}$ \\
\hline
\end{tabular}

serves to prevent, which denotes a wrong use of the diagnosis and prevention concepts.

Related to its universal nature, the concept of 'public good' appears as a reason to continue offering mammographies. The public 'good' is understood as general conditions that are advantageous to every person, regardless of their condition, facilitating equality. In this case, mammography is understood as a valuable resource that must be offered to women with the sole requirement of being aged 50-69 (table 3).

\section{Individual freedom as a reason to continue offering screening mammography}

Women's freedom to decide what to do once they are offered the opportunity to participate in screening mammography is revealed as another argument in favour of continuing the programme. There is the demand of being treated as active users of SSPA and not as mere passive users or consumers.
Such demand involves the participants' desire to be well informed and to be able to undertake responsibility in the form of decision making. Somehow, it is a way to reduce the anxiety that may be caused by the mammography, trying to increase control, and reduce ambiguity (table 3 ).

\section{Lack of efficacy as a reason not to continue offering screening mammography}

If efficacy was previously an argument to justify mammographies' continued offering, it is now an argument to question it. Some participants, such as Ana and Mercedes, question its efficacy and believe that, on some occasions, it depends on fate (table 3).

\section{High cost as a reason not to continue offering screening mammography}

Ana mentions the high cost of the screening programme and, in the face of the inefficacy of the test, considers the 


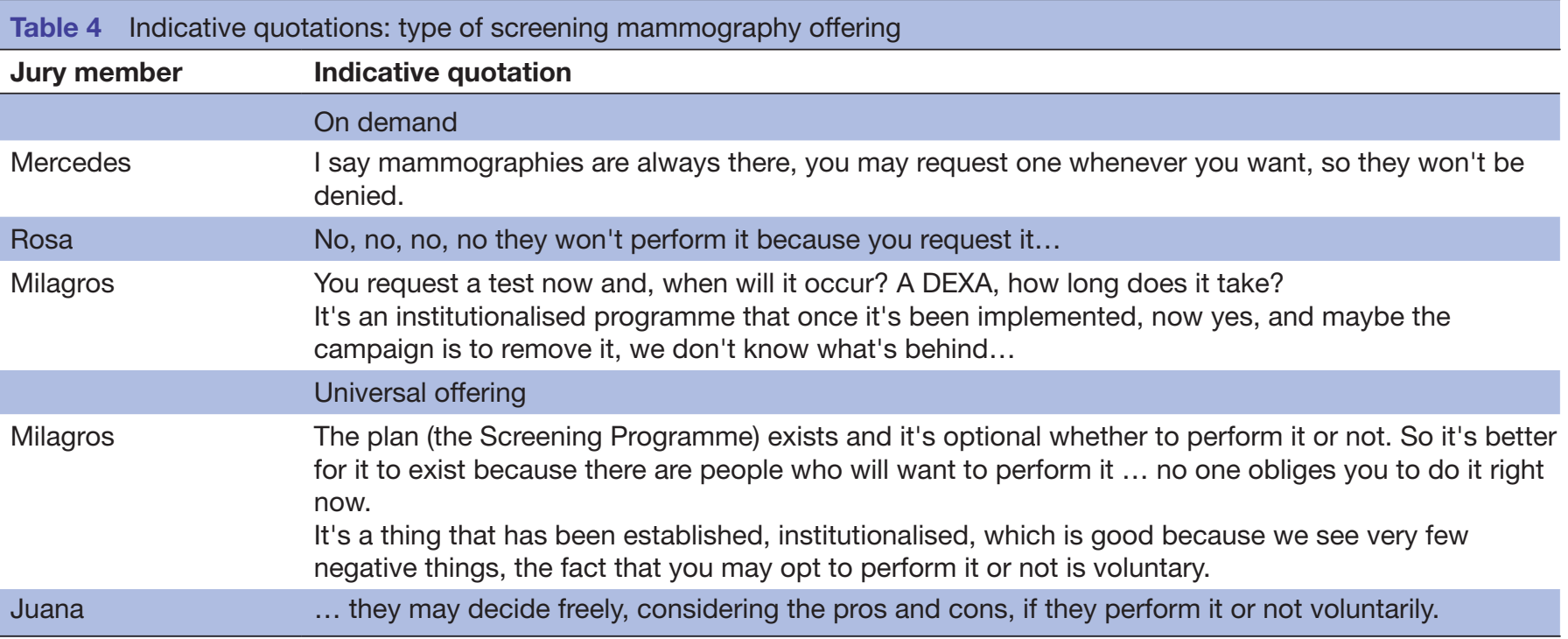

investment unjustified. That is why she suggests other measures, such as research, to make economic cost profitable and make progress regarding the issue (table 3).

\section{Availability on demand}

From the participants' words, there arises the idea that the SSPA must continue offering screening mammography, although there are some nuances. Some participants state that it must be offered on demand, that is, offered to those women requesting it. However, there are opinions against this possibility. Part of this rejection is based on the mistrust toward the SSPA and its good operation. Another part is based on the mistrust toward the latest goal of this research. Milagros expresses her fear related to the removal of the breast cancer screening programme's universal nature (table 3 ).

\section{Universal availability}

Some participants believe the screening test must continue being offered on a universal basis to women aged 50-69 since this does not make it compulsory. Therefore, the voluntary nature of participation is deemed a key feature (table 4).

\section{Recommendations to health authorities}

After joint consideration, the jury prepared a list of recommendations addressed to the health authorities to improve the screening mammography programme. They focused on the improvement of information, the psychology service demand and the promotion of research on breast cancer screening:

Recommendation 1: Women must be informed when receiving an invitation to participate in the programme so that their decision is informed (eg, being aware of the possibility of overdiagnosis, false positives, radiation).

Recommendation 2: Information must be given in such a manner that it is widely known (eg, information campaigns in the media, in particular, addressed to women aged 49-50).
Recommendation 3: During the screening test process, women must have specialised psychological support, particularly, in the case of evidence of the presence of disease.

Recommendation 4: Modify protocols of action after mammographies so that, in case there are signs of cancer, the patient may know to what tests they will be subjected.

Recommendation 5: Use less harmful techniques than mammographies and offer alternatives.

Recommendation 6: Provide more resources to research on breast cancer, its prevention, early diagnosis and treatment (eg, be able to select which women may benefit and which may be harmed on participation in the programme).

Recommendation 7: Studies on which the debate on benefits and cost of screening tests are based must be updated. The most recent ones are from the 1980s.

\section{DISCUSSION}

The deliberative democracy process has been feasible in a group of SSPA users and it has caused a favourable position, although the study information changed some participants' opinion (2 out of 13,15\%). This change should be considered more as a qualitative than as a quantitative assessment and be taken with caution due to the small sample size. From the analysis of the texts, it is clear that the participants improved their knowledge about the screening programme. Although there is no direct comparison with the degree of knowledge before the citizen jury, it is obvious that their knowledge was better than before; they were able to position themselves for or against, to comment on the universal offering or the demand for mammography and to express their opinion on its efficacy in terms of reducing mortality, its cost and different aspects of overdiagnosis.

On the grounds of health, test nature and individual freedom, women believe screening must continue being 
offered, and they make suggestions to the political authorities for them to improve information, psychology services and research. In general, most of them fight for maintaining or increasing medicalisation of their lives (not 'losing' mammographies and psychology services to fight problems derived therefrom), although there are women who invoke its lack of efficacy and cost to justify why it must not be offered, at least on a universal basis.

Although it is largely known that screening mammography is not perfect ${ }^{19}$ and despite the recommendation from the citizens' jury to reflect on its implementation, ${ }^{20}$ there are few deliberative experiences in relation thereto. The purpose of one of them was to collect recommendations on how to submit the information so that it would be easier for participants to make informed decisions on whether to attend a mammography or not. ${ }^{21}$ In another study, the citizens' jury mostly was against screening mammography for women under the age of 50 in New Zealand. ${ }^{22}$ Citizens' juries have been efficient in regard to changing the position of the population in the face of other screenings, such as prostate screenings. ${ }^{23}$ In our study, the change was limited but significant since $15 \%$ of participants now do not recommend screening.

The results of our deliberative democracy study may serve as a justification for political authorities to maintain screening mammography in women aged 50-69. However, we believe it would be interesting that they should consider studies indicating the harmful effects of the test, as well as the opinion of the participants who were against it, and that they also should reconsider the type of offering (universal vs on demand), although some experts think that if a screening is implemented, it must be for the entire population. ${ }^{24}$ This study has provided information on women at standard risk of breast cancer since mixing information about different risks or different screening tests exceeded the scope of the study. However, it is necessary to consider the power of pre-existing ideas and prevailing social speech that highlights the possible positive effects of screening mammography, barely considering negative arguments. ${ }^{325}$

Our study's implications for managers and clinical doctors must involve understanding the participants' claim of their right to choose freely. This involves placing such desire in the context where it occurs, which is characterised by the prevailing social speech in which, despite the lack of consent of the scientific community with respect to the benefits of the screening test, ${ }^{125-7}$ these are overvalued, thus disregarding its harm. Such social speech is motivated, among others, by awareness and sensitisation campaigns related to breast cancer that clearly show signs of lack of information ${ }^{26}$ and by the little information received by women who are invited to participate in the screening programme. ${ }^{4}$ Finally, screening mammography has been institutionalised ${ }^{27}$ in an increasingly medicalised $^{28}$ state determined by the logics of a consumption society in which women ${ }^{29}$ are immersed.

This study presents a series of weaknesses to be taken into account when considering the results, which must serve as elements to be strengthened in the future. The study was designed as a research project, so there was not a directive committee with the participation of women and without considering its critical perspective. ${ }^{1530}$ Nevertheless, the research team included expert witnesses, a moderator, a psychology expert in qualitative research and an expert in bioethics. The process lasted slightly less than recommended, ${ }^{15}$ but there was enough time to explore the issues addressed. The information submitted arises from a sole process of deliberative democracy, which is why it will be necessary to apply, as programmed, other methodological strategies allowing for the gathering of more information to fulfil the categories and be certain that the collected information covers every possibility. Apart from that, although the political authority accepted to be an observer interested in the project, there was no genuine commitment to incorporate results in their decisions.

Weaknesses closely related to the qualitative methodology have been detected at a procedural level. It has been observed that some participants did not pose every question they had and, therefore, they were not as well informed as was expected. The expert condition of the research team was highlighted, which could deepen the differences of power between the former and the participants and prevent their participation. Moreover, a certain hierarchy was observed among some participants.

Furthermore, certain mistrust is derived from the words toward the latest purposes of the research given that some participants are afraid that the SSPA might be considering the removal of mammographies. Said mistrust may have affected their opinions. Last, it must be considered that this work has been developed with a sample of literate women, with a medium-high level of education, economic resources, natives and without functional diversity. It would be necessary to perform works in other social realities whose needs must also be satisfied.

In conclusion, the deliberative strategy is feasible and causes a favourable position regarding screening mammography, although the information changes the opinion of some women, who desire informed decision making and to maintain or increase medicalisation in their lives (maintaining screening mammography and requesting psychological care to overcome the impact on them means maintaining or increasing the medicalisation of their lives).

\section{Author affiliations}

${ }^{1}$ Department of Medical Oncology, Hospital Universitario Puerta del Mar, Cadiz, Spain

${ }^{2}$ Department of Psychology, School of Educational Sciences, Universidad de Cadiz, Cadiz, Spain

${ }^{3}$ Department of Medical Oncology, Hospital Universitario Puerta del Mar, Cadiz, Spain

${ }^{4}$ Hospital Universitario de Puerto Real, Medical Oncology, Puerto Real, Andalucía, Spain

${ }^{5}$ Population Cancer Registry, Provincial Office of Health, Cádiz, Spain

${ }^{6}$ Servicio de Calidad y Procesos, Junta de Andalucia Consejeria de Salud, Sevilla, Spain 
${ }^{7}$ Ethics Committee Bahía de Cádiz - La Janda, Hospital Universitario Puerta del Mar, Cadiz, Spain

Acknowledgements The authors thank the study participants who generously offered their time and crucial insight into this research topic. The authors also thank the technician specialising in audiovisual media, D. Miguel Vaca Bohórquez, for his excellent work. We would also like to thank the transcription of deliberation days and the contributions to the report by the collaborating students of the School of Psychology, María José Escalona Castro, Pablo Terrada Ruíz, and M ${ }^{a}$ del Mar Jiménez Pérez. We would like to thank $\mathrm{M}^{\mathrm{a}}$ Isabel Herrera Sánchez for her participation in the information triangulation process.

Contributors JMBC conceptualised the project. JMBC, VLR, AQC, PRV, EBR, SMC, and JMRB contributed to the design and methodology. VLR and AQC performed analysis of the texts. JMBC, VLR, AQC, PRV, EBR, SMC and JMRB contributed to the development of the process of deliberative democracy (investigation). JMBC contributed key resources. VLR, AQC and PRV contributed to data curation and management. JMBC wrote the original first draft of the article. JMBC, VLR, AQC, PRV, EBR, SMC and JMRB played key roles in writing with respect to review and editing (all authors contributed to the final article). JMBC, VLR and PRV provided oversight and leadership (supervision).

Funding This work was supported by the Ministry of Health, Equality, and Social Policies through Project Grant number PI-0130-2014.

Competing interests None declared.

Patient consent Obtained.

Ethics approval This study was approved by The Bahía de Cádiz, La Janda Ethics Committee.

Provenance and peer review Not commissioned; externally peer reviewed.

Data sharing statement Presentations of the moderator and experts, and recordings and texts analysed during the current study are available from the corresponding author on reasonable request.

Open Access This is an Open Access article distributed in accordance with the Creative Commons Attribution Non Commercial (CC BY-NC 4.0) license, which permits others to distribute, remix, adapt, build upon this work non-commercially, and license their derivative works on different terms, provided the original work is properly cited and the use is non-commercial. See: http://creativecommons.org/ licenses/by-nc/4.0/

(C) Article author(s) (or their employer(s) unless otherwise stated in the text of the article) 2018. All rights reserved. No commercial use is permitted unless otherwise expressly granted.

\section{REFERENCES}

1. Harris RP, Wilt TJ, Qaseem A. for the High Value Care Task Force of the American College of Physicians. A value framework for cancer screening: advice for high-value care from the American College of Physicians. Ann Intern Med 2015;162:712-7.

2. Gøtzsche PC. Mammography screening is harmful and should be abandoned. J R Soc Med 2015;108:341-5.

3. Hoffmann TC, Del Mar C. Patients' expectations of the benefits and harms of treatments, screening, and tests: a systematic review. JAMA Intern Med 2015;175:274-86.

4. Baena-Cañada JM, Rosado-Varela P, Expósito-Álvarez I, et al. Women's perceptions of breast cancer screening. Spanish screening programme survey. Breast 2014;23:883-8.

5. Gigerenzer G, Mata J, Frank R. Public knowledge of benefits of breast and prostate cancer screening in Europe. J Natl Cancer Inst 2009;101:1216-20.

6. Jørgensen KJ, Gøtzsche PC. Content of invitations for publicly funded screening mammography. BMJ 2006;332:538-41.

7. Schwartz LM, Woloshin S, Sox HC, et al. US women's attitudes to false positive mammography results and detection of ductal carcinoma in situ: cross sectional survey. BMJ 2000;320:1635-40.
8. Stacey D, Légaré F, Col NF, et al. Decision aids for people facing health treatment or screening decisions. Cochrane Database Syst Rev 2014;1:CD001431.

9. Jimbo M, Rana GK, Hawley S, et al. What is lacking in current decision aids on cancer screening? CA Cancer J Clin 2013;63:193-214.

10. Martínez-Alonso M, Carles-Lavila M, Pérez-Lacasta MJ, et al. Assessment of the effects of decision aids about breast cancer screening: a systematic review and meta-analysis. BMJ Open 2017;7:e016894.

11. Lauby-Secretan B, Scoccianti C, Loomis D, et al. Breast-cancer screening--viewpoint of the IARC Working Group. N Engl J Med 2015;372:2353-8.

12. Biller-Andorno $N$, Jüni $P$. Abolishing mammography screening programs? A view from the Swiss Medical Board. N Engl J Med 2014;370:1965-7.

13. Márquez $S$, Lacalle JR. Beneficios y efectos adversos del cribado de cáncer de mama: revisión de la evidencia científica. Secretaría General de Salud Pública, Inclusión Social y Calidad de Vida. Consejería de Salud y Bienestar Social. Enero 2013.

14. Smith G, Wales C. Citizen's juries and deliberative democracy. Polit Stud 2000;48:51-65.

15. Street J, Duszynski K, Krawczyk S, et al. The use of citizens' juries in health policy decision-making: a systematic review. Soc Sci Med 2014;109:1e9.

16. Rychetnik L, Carter SM, Abelson J, et al. Enhancing citizen engagement in cancer screening through deliberative democracy. $J$ Natl Cancer Inst 2013;105:380-6.

17. Irwig L, Glasziou P. Informed consent for screening by community sampling. Eff Clin Pract 2000;3:47-50.

18. Boston Women's Health Book Collective. Our bodies ourselves. New York: New England Free Press, 1971.

19. Marmot MG, Altman DG, Cameron DA, et al. The benefits and harms of breast cancer screening: an independent review. Br J Cancer 2013;108:2205-40.

20. Thornton $\mathrm{H}$, Baum M. 'Should a mammographic screening programme carry the warning: screening can damage your health!'? Br J Cancer 1999;79:691-2.

21. Khor Z. Citizens' Jury on information for women about breast screening. 2012 https://www.opm.co.uk/wp-content/uploads/ 2014/02/OPM-ICCS-Citizens-Jury-FINAL-REPORT-07012013.pdf (accessed 4 Mar 2017).

22. Paul C, Nicholls R, Priest P, et al. Making policy decisions about population screening for breast cancer: the role of citizens' deliberation. Health Policy 2008;85:314-20.

23. Thomas R, Glasziou P, Rychetnik L, et al. Deliberative democracy and cancer screening consent: a randomised control trial of the effect of a community jury on men's knowledge about and intentions to participate in PSA screening. BMJ Open 2014;4:e005691.

24. Altobelli E, Lattanzi A. Breast cancer in European Union: An update of screening programmes as of March 2014 (Review). Int J Oncol;2014:1785-92.

25. Yu J, Nagler RH, Fowler EF, Franklin Fowler E, et al. Women's awareness and perceived importance of the harms and benefits of mammography screening: results from a 2016 National Survey. JAMA Intern Med 2017;177:1381-1382.

26. Porroche-Escudero A. [Problematising disinformation in breast cancer awareness campaigns]. Gac Sanit 2017;31:250-2.

27. Lin KW, Gostin LO. A Public health framework for screening mammography: evidence-based vs politically mandated care. JAMA 2016;315:977-8.

28. Østerlie W, Solbjør M, Skolbekken JA, et al. Challenges of informed choice in organised screening. J Med Ethics 2008;34:e5.

29. Ploug T, Holm S, Brodersen J. To nudge or not to nudge: cancer screening programmes and the limits of libertarian paternalism. $J$ Epidemiol Community Health 2012;66:1193-6.

30. Thomas R, Sims R, Degeling C, et al. CJCheck Stage 1: development and testing of a checklist for reporting community juries - Delphi process and analysis of studies published in 1996-2015. Health Expect 2017;20. 